\title{
Aerodynamic Analyses of Horizontal Axis Wind Turbine By Different Blade Airfoil Using Computer Program
}

\author{
ARVIND SINGH RATHORE ${ }^{1}$, SIRAJ AHMED ${ }^{2}$ \\ ${ }^{1}$ (Department of Mechanical Engineering Maulana Azad National Institute of Technology, Bhopal) \\ ${ }^{2}$ (Department of Mechanical Engineering Maulana Azad National Institute of Technology, Bhopal)
}

\begin{abstract}
:
An aerodynamic analysis tool for analysis of horizontal axis wind turbine blades is developed by using both Blade Element Momentum (BEM) Theory and Computer Program. The method is used to optimize blade geometry to give the maximum power for a given wind speed, a constant rotational speed, a number of blades and a blade radius. The airfoil profiles and their aerodynamic data are taken from an existing airfoil database for which experimental lift and drag coefficient data are available. The goal of this study was to analyze the effects of different airfoil profiles blade on the overall wind turbine performance.
\end{abstract}

Keywords - Aerodynamics, BEM Theory, Blade Profile, Computer Program

\section{INTRODUCTION}

The objectives of this study are to develop a method using BEM theory for aerodynamic design of the HAWT blades and performance analysis using different airfoil profiles, also to build a computer program, finally to determine the aerodynamic characteristics and to create the performance curves.

Airfoil information is used explicitly in the optimization process. Wind tunnel test data of several airfoils which are publicly available are collected and stored as an airfoil database. This database includes Lift, Drag and Angle of Attack data of many airfoils developed for or used in wind turbine applications $[1,2]$. Wind turbine blade is divided into number of sections along the blade. In the optimization process, airfoils are taken from the aerodynamic database, chord and twist distributions of the turbine blade is optimized to give the best power output for given number of blades, a blade radius, wind speed and rotational speed. As a result, an aerodynamic optimization tool is developed.

\section{METHOD}

\subsection{Blade Element Momentum (BEM) Theory:}

Blade Element Momentum Theory or Strip Theory basically aims to model the axial and tangential induction factors by equating the force and torque relations derived from each blade element and momentum theories [3]. In the Momentum Theory, the flow around a wind turbine can be modeled as an actuator disc as shown in the Fig.1. Basic assumptions used in the theory are the homogeneous, steady, uniform, axisymmetric, incompressible flow, wake is assumed non-rotating and turbulence effects are assumed unimportant. The mass flow rate across the disc is also assumed to be constant.

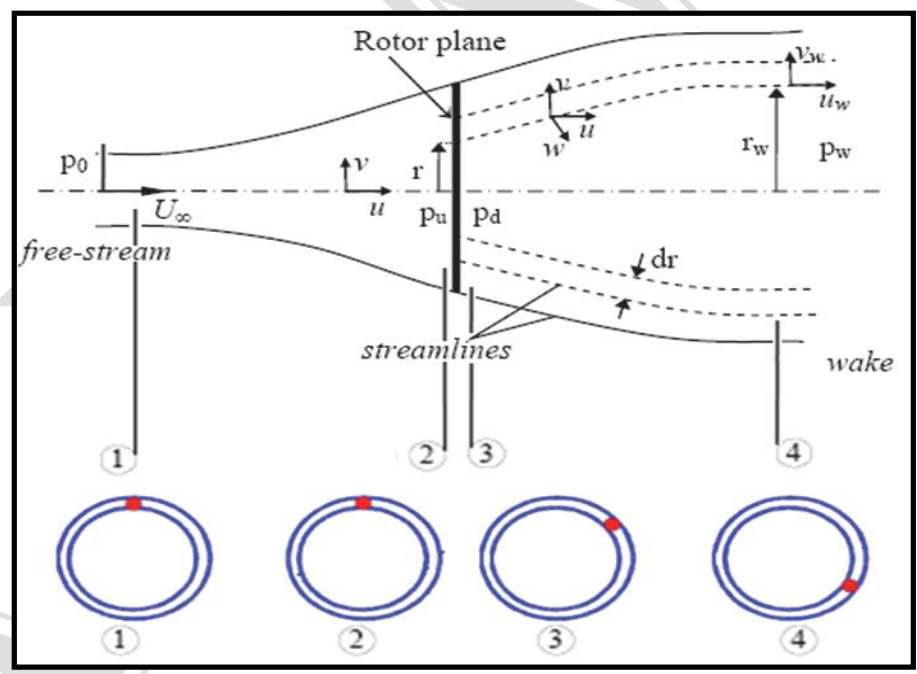

Fig.-1

2.2 Corrections used in BEM Theory:

Blade Element Momentum Theory is a simple theory based on quite a few assumptions. To compensate for certain inaccuracies some corrections are usually applied. The corrections used in this study are the turbulent wake corrections and tip loss corrections. These corrections and their applications are given in reference [7]. Basically, when the turbulence effects become strong, induction factors are evaluated with a modified formula. In addition, Prantl's tip loss model is applied to the loading distribution of the blade for the tip loss correction.

Prandtl tip-loss factor is given by the following equation [4, 5]

$$
F=(2 / \pi) \cos ^{-1}\left[\exp \left[\frac{-(B / 2)[1-(r / R)]}{(r / R) \sin \varphi}\right]\right]
$$

In the Blade Element Theory, blade is divided into several elements and in each element it is assumed that the performance 


\section{ARVIND SINGH RATHORE, SIRAJ AHMED / IOSR Journal of Engineering (IOSRJEN) \\ www.iosrjen.org

Vol. 2 Issue 1, Jan.2012, pp. 118-123

of the overall blade can be derived from the $2 \mathrm{D}$ airfoil which is used at that section by integrating it throughout the blade. Using the induction factor definitions, conservation of linear momentum and conservation of angular momentum equations are derived from blade element and momentum theories separately. The detailed derivations and explanations may be found in $[4,6]$. Hence, in the Blade Element Momentum (BEM) Theory, a, a and $\sigma$ are given by:

$$
\begin{aligned}
\sigma & =\mathrm{B} \mathrm{c} / 2 \pi \mathrm{r} \\
a & =\frac{1}{\left[1+\left[4 F \sin ^{2} \varphi /\left(\sigma C_{L}\right) \cos \varphi\right]\right]} \\
a^{\prime} & =\frac{1}{\left[\left[4 F \cos \varphi /\left(\sigma C_{l}\right)\right]-1\right]}
\end{aligned}
$$

To find out the maximum power coefficient for a selected airfoil type, dividing the blade length into $N$ elements, the local tip speed ratio for each blade element can then be calculated with the use of following equation [5]:

Local Tip Speed Ratio

$\Lambda_{\mathrm{r}, \mathrm{i}}=\lambda\left(\mathrm{r}_{\mathrm{i}} / \mathrm{R}\right)$

Optimum Relative wind for each blade element

$$
\begin{aligned}
& \varphi_{\text {opt }, i}=(2 / 3) \tan ^{-1}\left(1 / \lambda_{r, i}\right) \\
& a=(1 / F)\left[0.143+\sqrt{0.0203-0.6427\left(0.889-C_{T}\right)}\right]
\end{aligned}
$$

Tip- loss factor for each blade element

$$
F_{i}=(2 / \pi) \cos ^{-1}\left[\exp \left[\frac{-(B / 2)\left[1-\left(r_{i} / R\right)\right]}{\left(r_{i} / R\right) \sin \varphi_{\text {opt }, i}}\right]\right]
$$

Twist distribution:

$$
\theta_{i}=\varphi_{o p t, i}-\alpha_{\text {design }}
$$

Chord length distribution:

$$
c_{i}=\frac{8 \pi r_{i} F_{i} \sin \varphi_{o p t, i}}{B C_{L, d e s i g n}} \frac{\left(\cos \varphi_{o p t, i}-\lambda_{r, i} \sin \varphi_{o p t, i}\right)}{\left(\sin \varphi_{o p t, i}+\lambda_{r, i} \cos \varphi_{o p t, i}\right)}
$$

Power coefficient

$$
C_{p}=\sum_{i=1}^{N}\left[\begin{array}{l}
\left(\frac{8 \Delta \lambda_{r}}{\lambda^{2}}\right) F_{i} \sin ^{2} \varphi_{o p t, i}\left(\cos \varphi_{o p t, i}-\lambda_{r, i} \sin \varphi_{o p t, i}\right) \ldots \\
\left(\sin \varphi_{o p t, i}+\lambda_{r, i} \cos \varphi_{o p t, i}\right)\left[1-\left(C_{D} / C_{L}\right) \cot \varphi_{o p t, i}\right] \lambda_{r, i}^{2}
\end{array}\right]
$$

\subsection{Airfoil Database:}

The airfoil profiles are obtained from an airfoil database. The database contains airfoils that are designed or used for wind turbine applications. The lift and drag coefficients of the airfoils, that are based on wind tunnel test, are listed for various angles of attack and Reynolds numbers. The details of the database and the airfoil sections employed are given in reference [7].

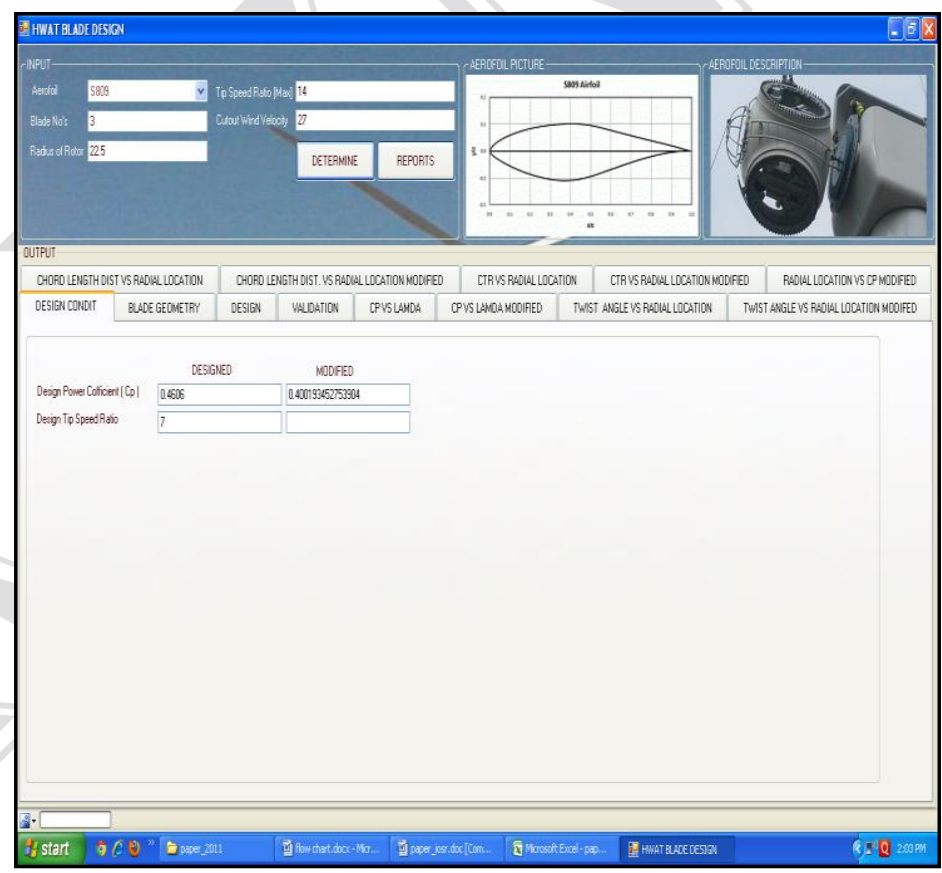

Fig.-2

\subsection{Computer Program:}

Applying the design procedure explained a computer program is written in $\mathrm{C}$-Sharpe Language using .NET Framework 4 to estimate the aerodynamic performance of the various airfoil profiles. A detailed flow chart of the program is given in Fig.-3.

The program take airfoil data, wind speed, radius of rotor, no of blades, density of air as input, no of blade elements and cut-out wind velocity as input. After calculation aerodynamic characteristic of different airfoil blades are plotted as output. In the blade design from root, tip and middle section taking the same airfoil. For comparing characteristic of airfoils, blade length taken as $21 \mathrm{~m}$ and hub diameter $45 \mathrm{~m}$. 
Vol. 2 Issue 1, Jan.2012, pp. 118-123

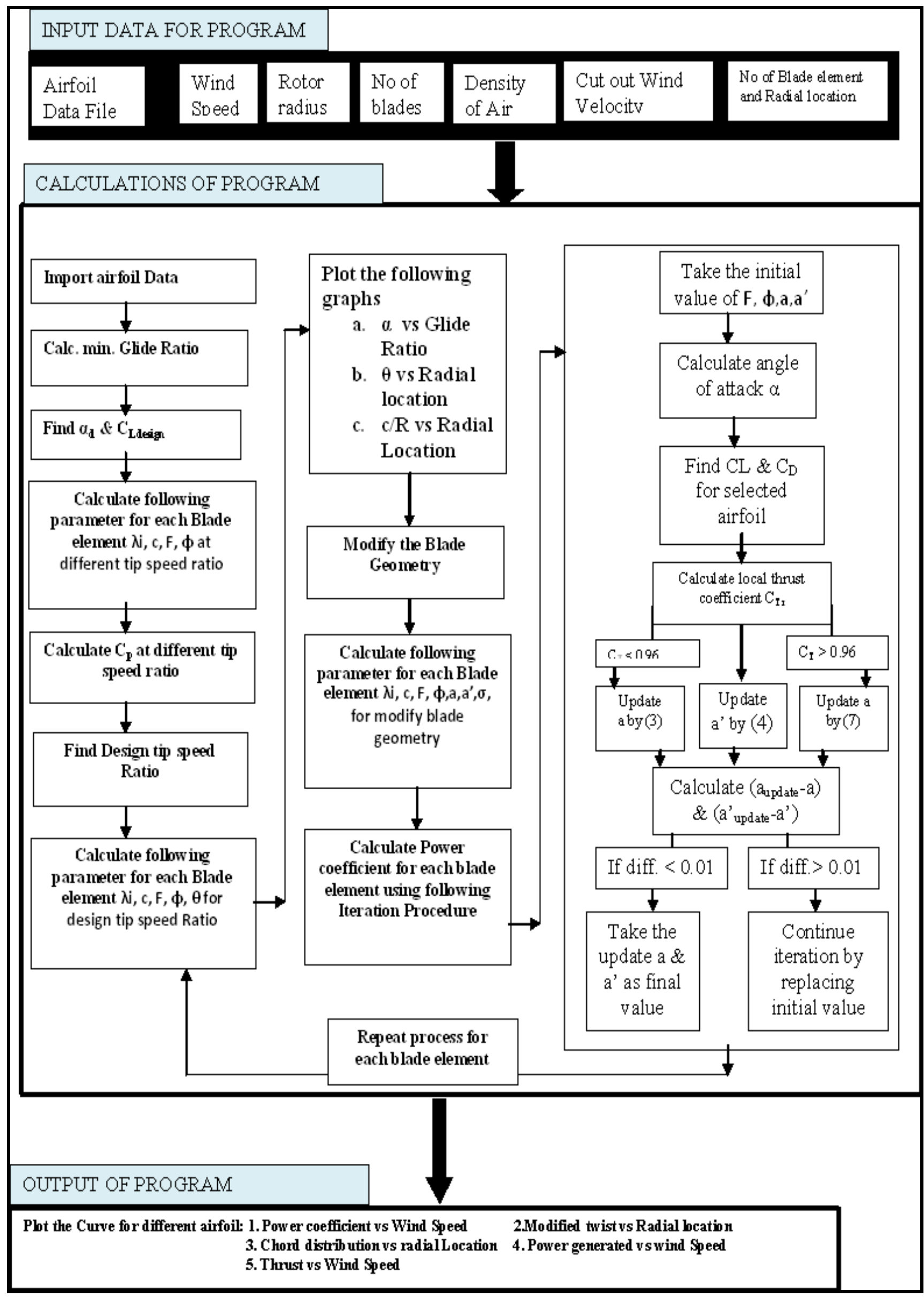

Fig.-3 
Vol. 2 Issue 1, Jan.2012, pp. 118-123

\section{RESULTS:}

3.1 Variation of power coefficient with Tip speed ratio

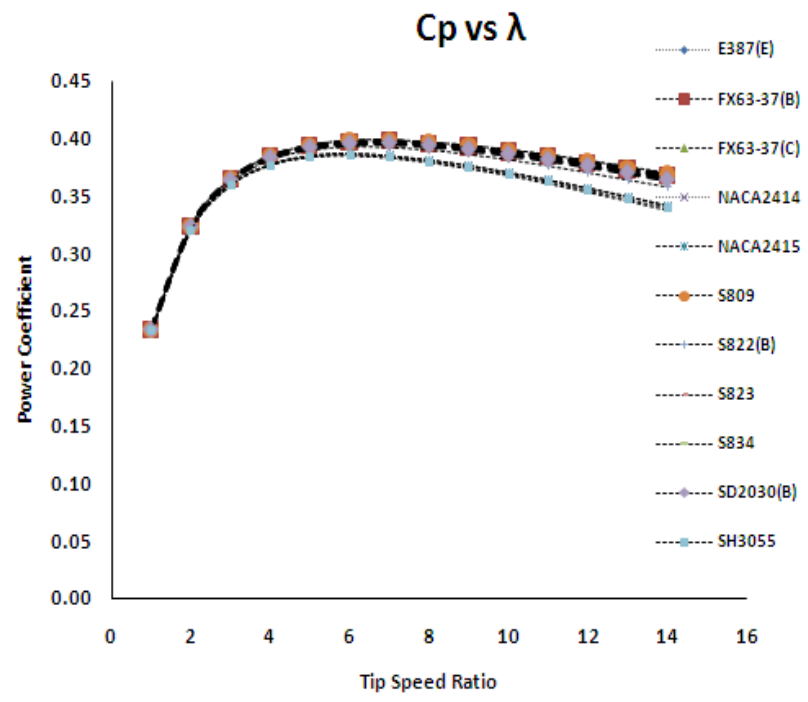

Fig. -4

Power coefficient is increases as tip speed ratio increases but after certain limit it decreases for all the airfoil. Tip speed ratio at which power coefficient is maximum is called design tip speed ratio.

3.2 variation of chord distribution with radial location

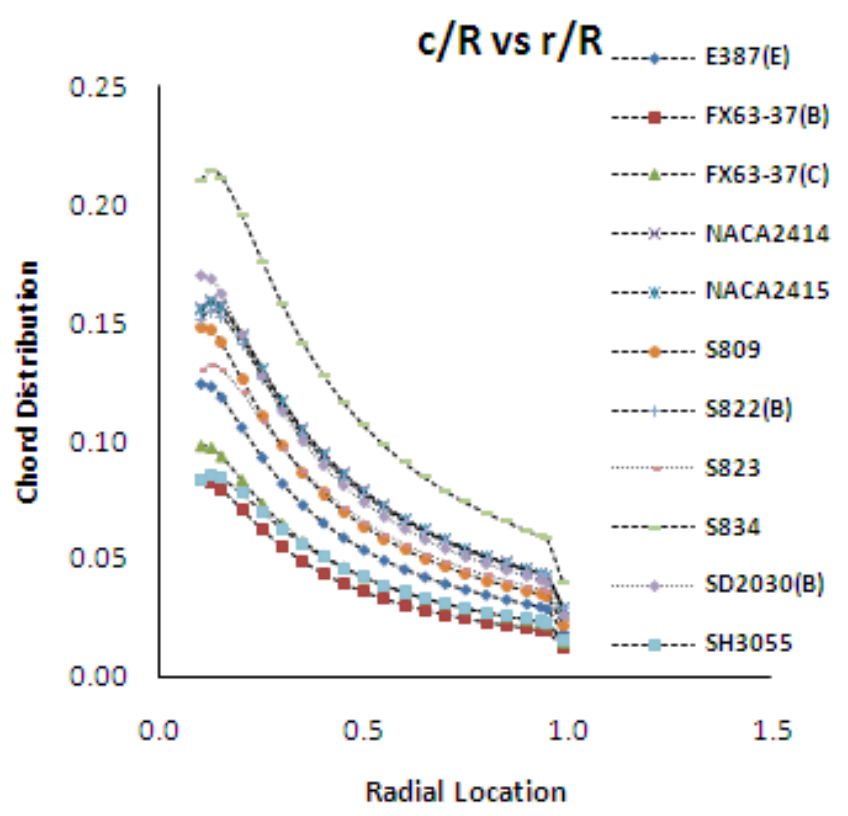

Fig. -5

Chord is maximum at root section and is minimum at tipsection. We can notice that the decreasing of chord length is not linear with the increasing of the radius.
3.3 Variation of twist with radial location.

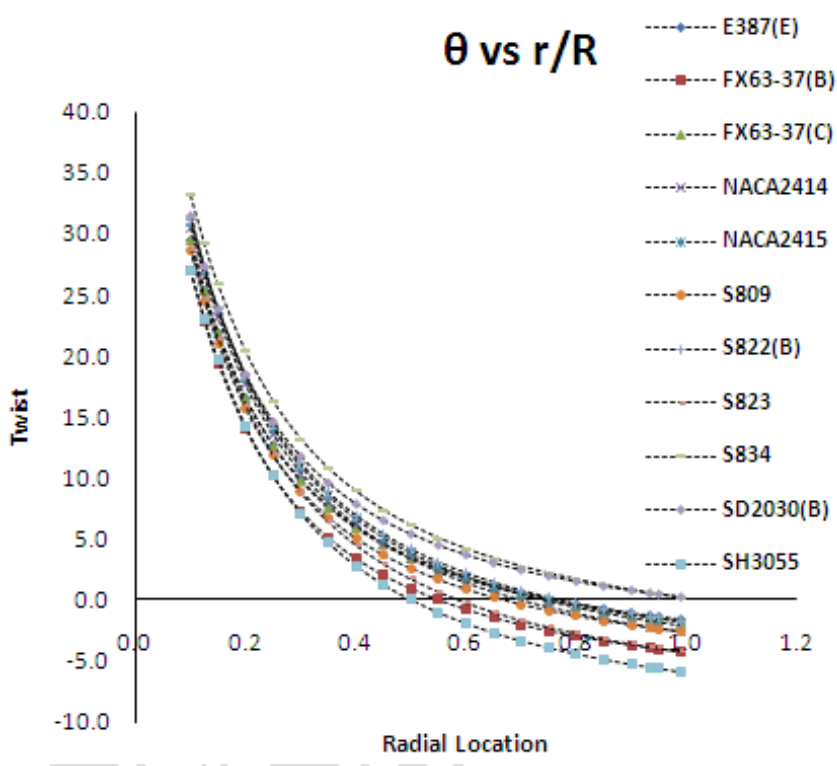

Fig.-6

Twisting angle is also decreases from root to tip and it is negative near the tip-section.

3.4 Variation of modified chord distribution with radial location.

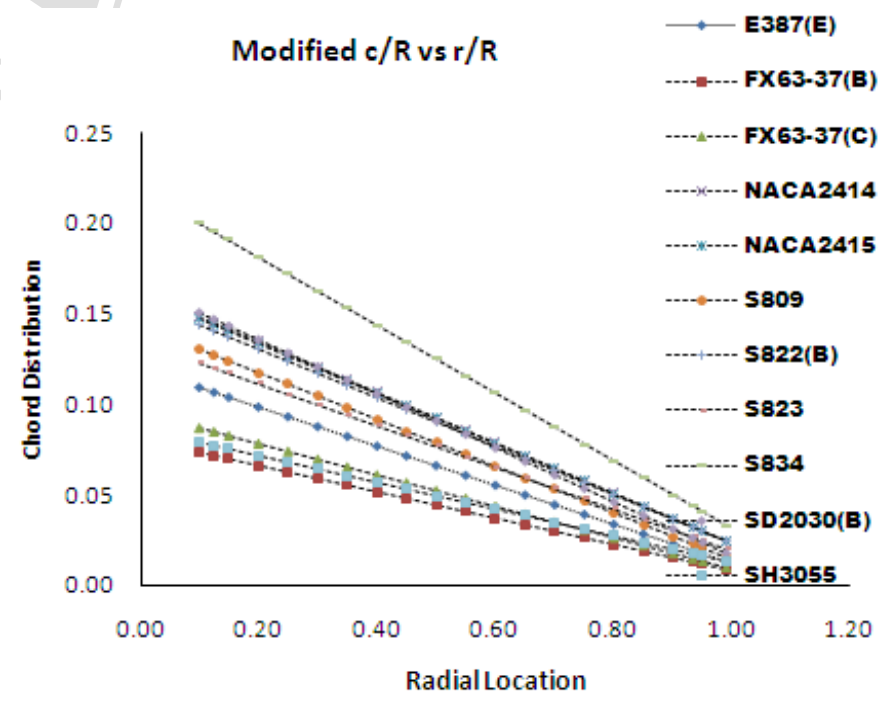

Fig-7

Chord is modified for improving the aerodynamic property of blade and makes the chord distribution linear. 
Vol. 2 Issue 1, Jan.2012, pp. 118-123

3.5. Variation of modified twist with radial location

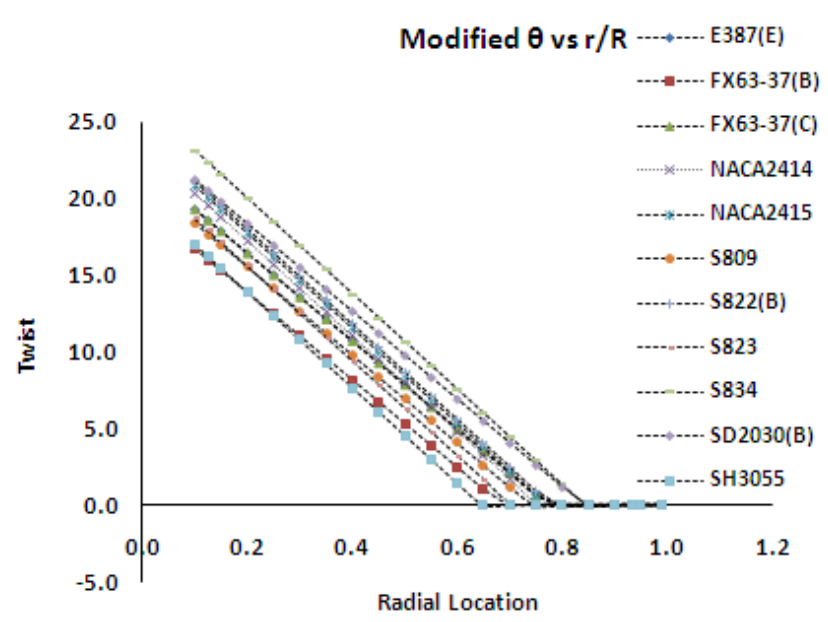

Fig. -8

This modification has been performed such that twist distribution of the modified blade has been linearized. Also at some distance from blade root the twist becomes negative which generally causes the blade elements from this distance to blade tip to be stalled. To prevent these blade elements from being in stall region, their twist values are set to zero.

3.6. Variation of Power generated with wind velocity

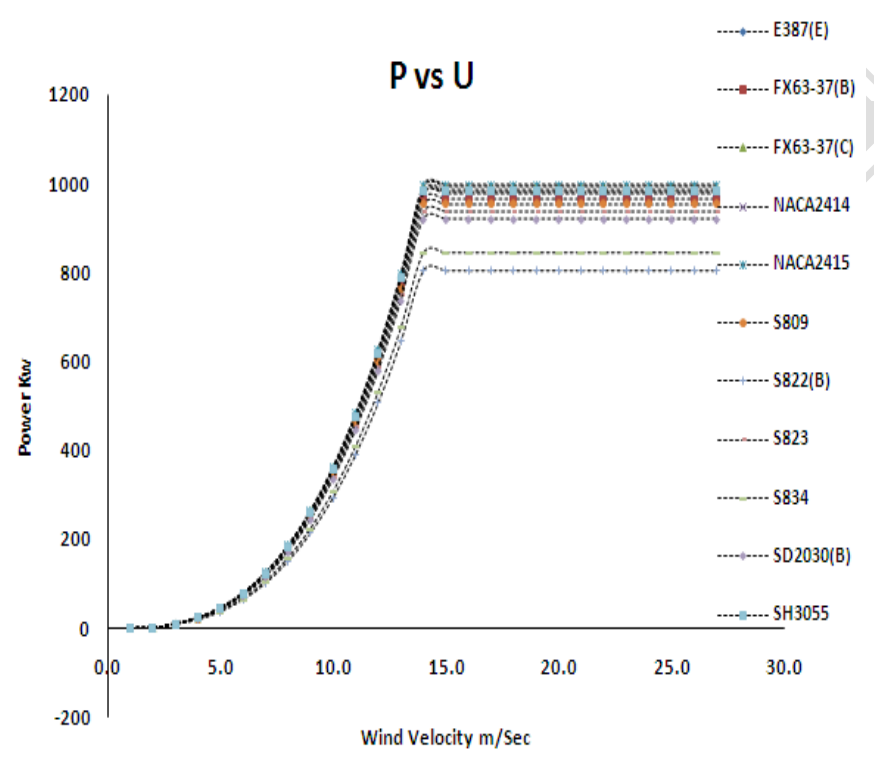

Fig.-9

Power increases with wind speed, it is maximum at nominal wind velocity $14 \mathrm{~m} / \mathrm{sec}$ and maximum power generated by NACA-2415 airfoil.

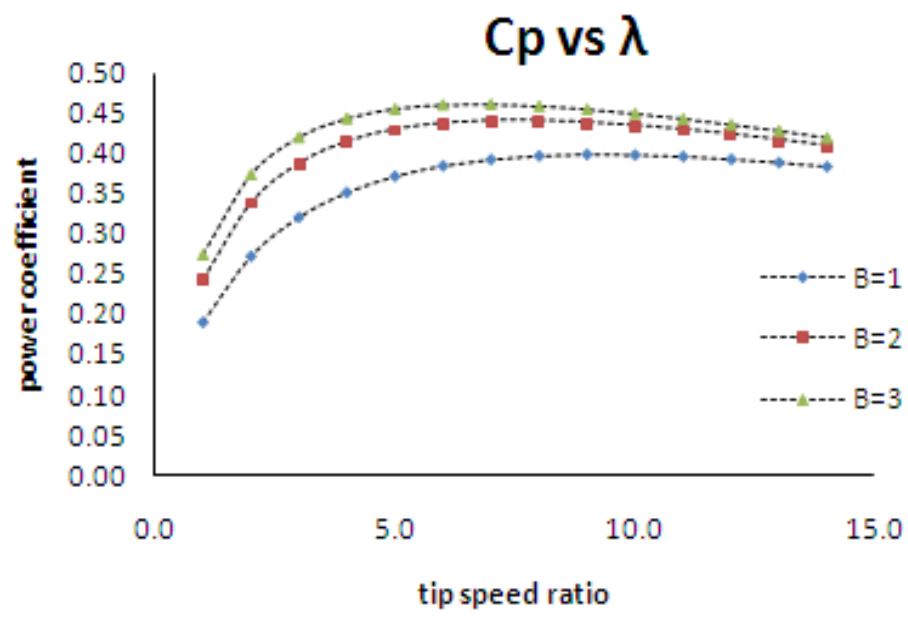

Fig.-10

3.8 View of blade airfoil from root to tip

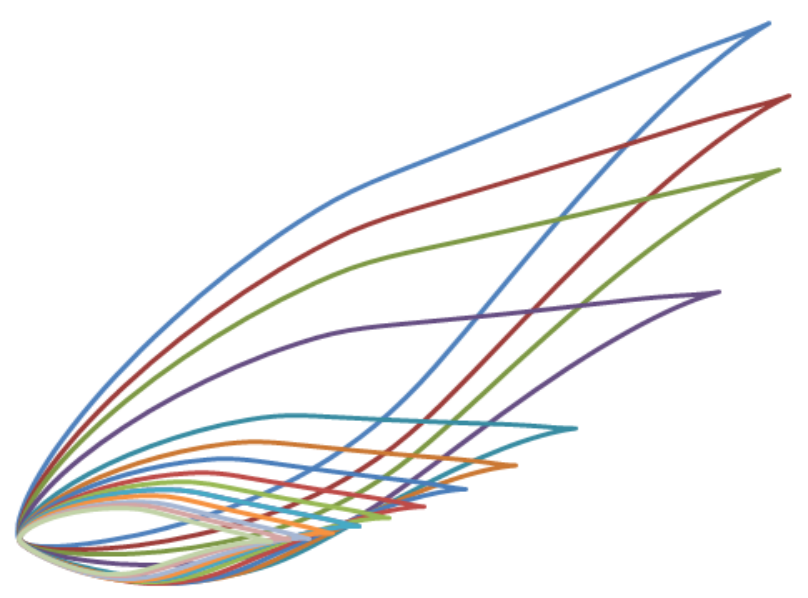

Fig.-11

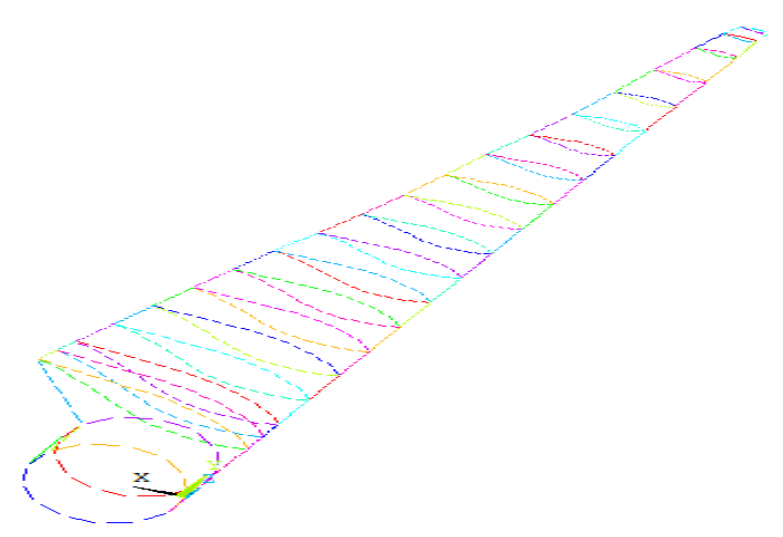

Fig.-12

3.7 Variation of power coefficient with no of blades 
Vol. 2 Issue 1, Jan.2012, pp. 118-123

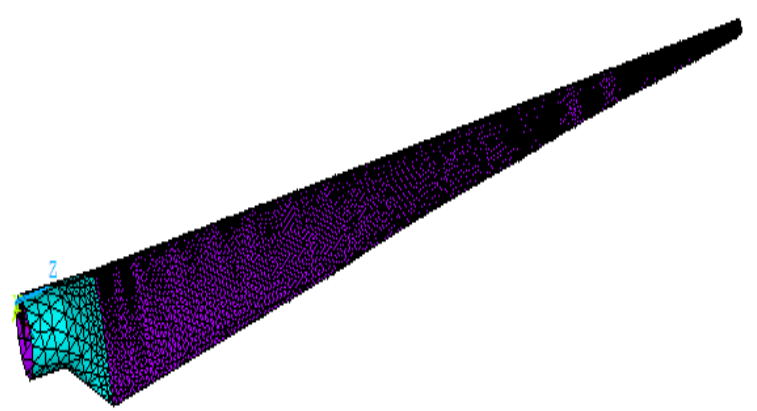

Fig.-13

\section{CONCLUSION}

In this paper a computer program is used for analysis of aerodynamics of different airfoil. We take the 11 airfoils data for $21 \mathrm{~m}$ length of blade out of which NACA-2415 airfoil has generated maximum power at nominal wind velocity. This program can be used for any number of airfoils.

\section{References:}

[1] Michael S. Selig and Bryan D. McGranahan " Wind Tunnel Aerodynamic Tests of Six Airfoils for Use on Small Wind Turbines" January 31, 2003

Eke G.B., Onyewudiala J.I. "Optimization of Wind Turbine Blades Using Genetic Algorithm"Global Journal of Researches in Engineering 22 Vol. 7 (Ver 1.0), December 2010.

[3] Ali Vardar, Ilknur Alibas, "Research on wind turbine rotor models using NACA profiles"; Renewable Energy 33 (2008) 1721-1732

[4] Manwell, J. F., McGowan, J. G., Rogers, A. L., "Wind Energy Explained; Theory, Design and Application”, John Wiley \& Sons Ltd, 2002

[5] Spera, D. A., "Wind Turbine Technology", ASME Press, 1998

[6] J. F. Manwell, J. G. McGowan, A. L. Rogers Wing Energy, Theory, Design and Applications, Contract NAS2-11665, Muadyne Report 83-2-3, John Wiley and Sons, 2006.

[7] Ceyhan O., Aerodynamic Design and Optimization of Horizontal Axis Wind turbines by Using BEM Theory and Genetic Algorithm, Master Thesis, Aerospace Engineering Department, METU, Ankara, 2008.

\section{Nomenclature:}

$C_{p}$ : Power coefficient of wind turbine rotor

$P$ : Power output from wind turbine rotor

$m$ : Air mass flow rate through rotor plane

$U$ : Free stream velocity of wind

$U_{r e l}$ : Relative wind velocity

$U_{R}$ : Uniform wind velocity at rotor plane

$A$ : Area of wind turbine rotor

$R$ : Radius of wind turbine rotor

$r$ : Radial coordinates at rotor plane

$r_{\mathrm{i}}$ : Blade radius for the $\mathrm{i}^{\text {th }}$ blade element

$T$ : rotor thrust

$Q:$ rotor torque

$C_{D}$ : Drag coefficient of an airfoil

$C_{L}$ : Lift coefficient of an airfoil

$F$ : Tip-loss factor

$F_{i}$ : Tip-loss factor for the $\mathrm{i}^{\text {th }}$ blade element

$N$ : Number of blade elements

$B$ : Number of blades of a rotor

$a$ : Axial induction factor at rotor plane

$a^{\prime}$ : Angular induction factor

$\lambda$ : Tip-speed ratio of rotor

$\lambda_{d}$ : Design Tip- Speed ratio of rotor

$\lambda r$ : local Tip- Speed ratio of rotor

$\lambda r, i$ : Local tip-speed ratio for the $\mathrm{i}^{\text {th }}$ blade element

$C_{i}:$ : Blade chord length for the $\mathrm{i}^{\text {th }}$ blade element

$\rho$ : Air density

$\Omega$ : Angular velocity of wind turbine rotor

$\alpha:$ Angle of attack

$\theta_{i}$ : Pitch angle for the $\mathrm{i}^{\text {th }}$ blade element

$\varphi_{\text {opti: }}$ Optimum relative wind angle for the $\mathrm{i}^{\text {th }}$ blade element $\sigma$ : Solidity ratio

$v$ : Kinematic viscosity of air

$\gamma$ : Glide ratio

$R e$ : Reynolds number

$H A W T$ : Horizontal-axis wind turbine

BEM: Blade element momentum 